\section{Federation University ResearchOnline}

\section{https://researchonline.federation.edu.au}

Copyright Notice

This is the author's preprint version of the following publication:

Weiler, van Mechelen, W., Fuller, C., Ahmed, O. H., \& Verhagen, E. (2018). Do

Neurocognitive SCAT3 Baseline Test Scores Differ Between Footballers (Soccer) Living With and Without Disability? A Cross-Sectional Study. Clinical Journal of Sport Medicine, 28(1), $43-50$.

The version displayed here may differ from the final published manuscript.

The final published manuscript is available at Emerald Insight via:

https://doi.org/10.1097/JSM.0000000000000407

Copyright @ 2017 Wolters Kluwer Health Inc.

See this record in Federation ResearchOnline at:

http://researchonline.federation.edu.au/vital/access/HandleResolver/1959.17/165210 


\title{
Do Neurocognitive SCAT3 Baseline Test Scores Differ Between Footballers (Soccer) Living With and Without Disability? A Cross-Sectional Study
}

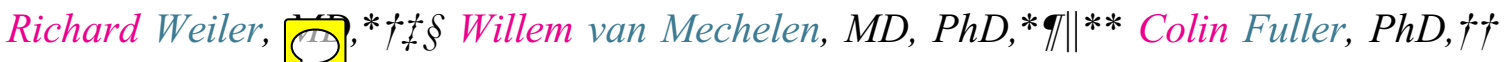

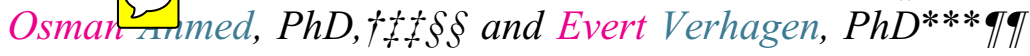

\begin{abstract}
Objective: To determine if baseline Sport Concussion Assessment Tool, third Edition (SCAT3) scores differ between athletes with and without disability.
\end{abstract}

Design: Cross-sectional comparison of preseason baseline SCAT3 scores for a range of England international footballers.

Setting: Team doctors and physiotherapists supporting England football teams recorded players' SCAT 3 baseline tests from August 1, 2013 to July 31, 2014.

Participants: A convenience sample of 249 England footballers, of whom 185 were players without disability (male: 119; female: 66) and 64 were players with disability (male learning disability: 17; male cerebral palsy: 28; male blind: 10; female deaf: 9).

Assessment and Outcome Measures: Between-group comparisons of median SCAT3 total and section scores were made using nonparametric Mann-Whitney-Wilcoxon ranked-sum test.

Main Results: All footballers with disability scored higher symptom severity scores compared with male players without disability. Male footballers with learning disability demonstrated no significant difference in the total number of symptoms, but

Submitted for publication July 15, 2016; accepted October 9, 2016

From the *Amsterdam Collaboration on Health and Safety in Sports, Department of Public and Occupational Health, EMGO Institute for Health and Care Research, VU University Medical Center, Amsterdam, the Netherlands; †The FA Centre for Disability Football Research, St Georges Park, Burton-Upon-Trent, Staffordshire, United Kingdom; †University College London Hospitals NHS Foundation Trust, London, United Kingdom; §Fortius Clinic, London, United Kingdom; $₫$ School of Human Movement and Nutrition Sciences, Faculty of Health and Behavioural Sciences, University of Queensland, Brisbane, Australia; ||School of Public Health, Physiotherapy and Population Sciences, University College Dublin, Dublin, Ireland; **Division of Exercise Science and Sports Medicine (ESSM), Department of Human Biology, Faculty of Health Sciences, University of Cape Town (SO) th Africa; ††Colin Fuller Consultancy Ltd, Sutton Bonington, Unit ngdom; +Dapartment of Physiotherapy, Poole Hospital NHS Foundation Trust, Po Inited Kingdom; §§Faculty of Health and Social Sciences, Bournemoutrr University, Bournemouth, United Kingdom; and $\uparrow \mid$ Australian Centre for Research into Injury in Sport and its Prevention, Federation University Australia, Ballarat, Victoria, Australia.
R. W ancers anceived the concept of this paper, collated, and analyzed the data. All 1 utD $r$ participated in reviewing, editing the ideas in this paper. R. Werrar and E. Verhagen generated the primary draft of this paper, and all authors then assisted in creating the final version of this paper.

Corresponding Author: $\mathrm{R}$ Weiler, Copyright (C) 2016 Wolte 2 wer Healt 2 . All rights reserved. recorded significantly lower scores on immediate memory and delayed recall compared with male players without disability. Male blind footballers' scored significantly higher for total concentration and delayed recall, and male footballers with cerebral palsy scored significantly higher on balance testing and immediate memory, when compared with male players without disability. Female footballers with deafness scored significantly higher for total concentration and balance testing than female footballers without disability.

Conclusions: This study suggests that significant differences exist between SCAT3 baseline section scores for footballers with and without disability. Concussion consensus guidelines should recognize these differences and produce guidelines that are specific for the growing number of athletes living with disability.

Key Words: concussion, neurocognitive testing, SCAT, disability sport

(Clin J Sport Med 2016;00:1-8)

\section{INTRODUCTION}

The World Health Organization (WHO) estimates that there is over one billion people worldwide living with disability. ${ }^{\mathbf{1}}$ People living with disability gain numerous positive health and social benefits from regular exercise and participation in team sports (such as basketball, football, and rugby). ${ }^{1-4}$ In England, the "Active People Survey 7" confirmed that 1.7 million people living with disability play sport, of which, 85600 play "disability football" at least once a week. ${ }^{5}$ For these footballers, there are organized "pan-disability" football leagues and leagues specifically for those with hearing and visual impairment (including football for those with blindness and partially sighted); learning disability; cerebral palsy (including head injuries and eligible neurological conditions); power-chair users; and those living with amputation. Each of these forms of adapted football ensures that athlete eligibility is confirmed through classification systems that are unique to each of the sport's governing bodies. ${ }^{6,7}$ Despite a long history, growing popularity, and participation rates, ${ }^{5}$ very little is known about injury rates, management, or prevention in disability sports. ${ }^{8}$

There are more than 42 separate published definitions of concussion determined by consensus. ${ }^{9}$ The potential short, medium, and long-term consequences of concussion have become major issues in many sports, and these issues are at 
least as (if not more) important for athletes competing in disability sports. ${ }^{10}$ The authors of the fourth Consensus Statement on Concussion in Sport acknowledged that "science of concussion is evolving, and therefore management and return-to-play (RTP) decisions remain in the realm of clinical judgment on an individualized basis." 11 However, this consensus neither discusses nor makes reference to the large and growing population of athletes with disability and does not discuss the complex issues associated with managing concussion within disability sports. The position statement on concussion in sport by the American Medical Society for Sports Medicine (AMSSM), nevertheless, raises the issue and outlines complexities associated with managing concussion among athletes with certain disabilities. ${ }^{12}$

It is generally agreed that further research is needed to validate current concussion assessment tools to delineate the role of neuropsychological testing and to improve identification of those at risk of prolonged postconcussive symptoms or other long-term complications. ${ }^{12}$ This view is equally valid for disability sport. The Sport Concussion Assessment Tool, third Edition (SCAT3) provides a freely accessible internationally recognized tool supported by many sports governing bodies and describes itself as "the standardized tool for evaluating injured athletes for concussion." The tool is stated to be appropriate for use with all athletes aged 13 years and older. ${ }^{11,13}$ Preseason "baseline testing" of athletes with the SCAT3 is recommended in the concussion guidelines, with baseline test results helpful for interpreting postinjury test scores. However, the clinical value of SCAT3 testing when an athlete is well (ie, not concussed), and subsequent follow-up (pos cussion) testing is currently not supported by eviden 2 heither validated in athletes in general nor in athlete subgroups, such as those with disability. ${ }^{14}$ Although SCAT3 has not been validated, it has been generated by consensus and is recommended in clinical practice, thereby carrying certain associated important medico-legal clinical obligations. ${ }^{15,16}$

Hanninen et $\mathrm{al}^{17}$ recently reported representative normative SCAT3 references values for 304 male professional ice hockey players from Finland in a descriptive crosssectional study. They split test section scores into cut-off score ranges, based on distribution percentile ranks and categorized these as follows: "Broadly normal," "Above/ below average," "Unusually low/high," and "Extremely low/high," accounting for section scores that go up and down respectively and that score distribution was not normally distributed. There have been few studies analyzing noncussed neurocognitive scores for athletes with dis$\mathrm{ab}$ i. ; and the limited studies available suggest that

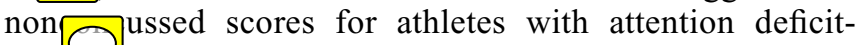
sper disorders and/or learning disability may differ from athletes without such diagnoses. ${ }^{18-20}$ However, none of these studies used the consensus recommended SCAT3 for testing. Other concussion position statements recommend neurocognitive testing more strongly for adolescent athletes at the beginning of a sporting career, athletes with learning disability, athletes with a previous history of concussion, and athletes who have recently suffered concussion. ${ }^{21-23}$ The SCAT3 recommends without further specification that it can be used for all athletes from the age of 13 years and makes no inferences on usability for athletes with disability. 11

In the absence of normative data for SCAT3 scores, and insights into the usability of SCAT3 for athletes with disability, the aim of this study was to determine whether differences exist between baseline SCAT3 scores for footballers with and without disability.

\section{METHODS}

\section{Study Design}

All En d team sports physicians and physiotherapists workit for England international football teams commenced recording baseline SCAT3 scores for all players in the season August 2013 to July 2014. In accordance with SCAT3 recommendations, baseline SCAT3 testing was introduced as a mandatory medical requirement by the Football Association in August 2013 for all England players before they train or compete for England, because "preseason baseline testing with the SCAT3 can be helpful for interpreting postinjury test scores." 11 This study provides a descriptive cross-sectional analysis of initial annual baseline SCAT3 test scores for English international footballers playing with and without disability.

\section{Population}

The population consisted of a convenience sample of 249 England international footballers after selection for their respective England team (male: 174, female: 75) who underwent SCAT3 baseline assessments. One hundred eighty-five were players without disability (male: 119; female: 66) and 64 with disability (male learning disability: 17; male cerebral palsy: 28; male blind: 10; female deaf: 9).

Age-related SCAT3 differences in year groups younger than 16 years of age are poorly understood. ${ }^{20,24}$ To avoid potential cognitive maturation confounding effects during the cross-sectional comparisons, only athletes older than the age of 16 years were included in this study. $., 25,26$ The eligibility criteria for players being categorized within each disability football squad were determined by formal international classification criteria. 6,7

\section{Ethics}

University College London Research Ethics Committee confirmed in writing that this study was exempt from the requirement to obtain ethics committee approval, as the study constituted a service provision evaluation of anonymous data extracted without individual identifiers.

\section{Outcome Measures}

All England team physicians and physiotherapists performed standardized baseline SCAT3 assessments on players when they were healthy (not concussed). Testing was conducted by experienced medical personnel (English registered and licensed physicians and physiotherapists; $(\mathrm{n}=16)$ who had successfully completed an advanced 
resuscitation and emergency aid (AREA) training course, which includes a section on concussion recognition, management, and the application of SCAT3).

The lead author (RW) evaluated every submitted SCAT3 form. SCAT3 forms with incomplete or illegible subsections were excluded $(n=8)$ from the analysis. Scores for each SCAT3 construct were calculated and recorded in accordance with the SCAT3 guidance, ${ }^{11,13}$ including

1. Symptom evaluation: total number (22 items; score range: 0-22) and severity (score range: 0-132);

2. Standardized assessment of concussion (SAC): orientation (score range 0-5), immediate memory (score range: 0-15), and concentration (score range: 0-5); total SAC score range: 0 to 25 ;

3. Balance examination: modified Balance Error Scoring System (BESS) testing (3 balance tests each with score range: $0-10$; total BESS score range: $0-30)$;

4. Coordination examination (upper limb finger-to-nose test repeated 5 times in less than 4 seconds): upper limb (test failure: 0; test pass: 1); and

5. SAC delayed recall: 5 words from immediate memory test after the balance and coordination examinations (score range: $0-5)$.

Although total SCAT3 score is not clinically recommended within the SCAT3 tool, it has since been recommended as being clinically useful ${ }^{25}$ so total SCAT3 score (range: 0-215) was also calculated by summing each SCAT3 subscore.

\section{Statistical Analyses}

IBM SPSS Statistics for Windows, Version 22.0 (IBM Corp, Armonk, New York) was used for statistical analyses. Median scores were compared using the nonparametric Mann-Whitney-Wilcoxon ranked-sum test because the results for SCAT3 subscores are skewed either to zero (eg, the symptom evaluation subscore) or to the maximum score (eg, the cognitive assessment subscore), which allowed null hypotheses to be tested for differences between athletes with and without disability. Statistical significance is accepted for $P \leq 0.05$ values. It is accepted that sex may be a risk factor for concussion and this may influence injury severity; $11,24,27-29$ therefore, initial analyses were performed to compare male and female SCAT3 subsection scores to determine if disability athletes should be compared separately by sex.

\section{RESULTS}

\section{Participants}

Table 1 summarizes the age (mean, SD, and range) and concussion history of the participants in the 6 player-groups. Of the 294 participants, $62(25.0 \%)$ reported having sustained a concussion, but only 8 of these concussions (all from nondisability groups) were sustained in the 6-month period preceding the baseline test. Twenty-seven of the 62 players who reported a previous concussion (43.5\%) returned to play/ training in less than 6 days.

\section{SCAT3 Scores}

Table 2 presents differences in median and range values for each SCAT3 section as a function of sex and disability or nondisability status. Comparison of median scores for male and female footballers without disability demonstrated that female scores were higher for the number of symptoms $(P<0.001)$, symptom severity $(P<0.001)$, and orientation $(P=0.006)$, and were lower for the median number of errors on the modified balance error scoring test $(P=0.003)$.

\section{Footballers Without Disability Versus Footballers With Disability}

Table 3 demonstrates multiple significant differences $(P<0.05)$ between SCAT3 subscores between male footballers with and without disability. All male and female footballers, including blind footballers, were able to complete the finger-to-nose coordination test (scoring one point); therefore, this test was not considered for further analysis. Orientation scores (Table 3) demonstrated no differences between the male footballer groups. Compared out disability, male footballers wit 20 ability scored significantly higher for symptom severity and footballers who were blind or had cerebral palsy scored significantly higher for total number of symptoms. However, male footballers with learning disability demonstrated no difference with total number of symptoms and scored significantly lower on immediate memory and delayed recall compared with male footballers without disability. Male blind footballers scored significantly higher for total concentration and delayed recall compared with male footballers without disability. Male footballers with cerebral palsy scored significantly higher on balance testing and significantly lower on immediate memory compared with male footballers without disability. Comparison of male footballers with and without disability showed significantly

TABLE 1. Characteristics at SCAT3 Assessment for Nonconcussed Footballers With and Without Disability

\begin{tabular}{|c|c|c|c|c|}
\hline Footballer Team & No. Athletes & Age Range & Mean Age (Mean \pm SD) & $\begin{array}{c}\text { No. Players Reporting a Previous } \\
\text { Concussion }(\%)\end{array}$ \\
\hline Learning disability (male) & 17 & $17-24$ & $19.9 \pm 2.4$ & $2(11.8)$ \\
\hline Cerebral palsy (male) & 28 & $16-28$ & $19.4 \pm 3.5$ & $9(32.1)$ \\
\hline Deaf (female) & 9 & $20-38$ & $24.0 \pm 5.6$ & $3(33.3)$ \\
\hline Blind (male) & 10 & $16-42$ & $27.9 \pm 7.7$ & $3(30.0)$ \\
\hline Nondi $y$ (male) & 119 & $16-28$ & $17.9 \pm 1.7$ & $30(25.2)$ \\
\hline Nondi: 2 y (female) & 66 & $16-31$ & $21.0 \pm 4.1$ & $15(22.7)$ \\
\hline
\end{tabular}


TABLE 2. SCAT3 Section Baseline Assessment Median and Range Values for Male and Female Footballer Groups With and Without Disability

\begin{tabular}{|c|c|c|c|c|c|c|}
\hline \multirow[b]{3}{*}{ SCAT3 Section } & \multicolumn{6}{|c|}{ Assessment Group; Median (Range) Score } \\
\hline & \multicolumn{2}{|c|}{ Groups Without Disability } & \multicolumn{4}{|c|}{ Groups With Disability } \\
\hline & Male & Female & Learning Disability, Male & Cerebral Palsy, Male & Blind, Male & Deaf, Female \\
\hline Symptom severity (max: 132) & $0(0-10)$ & $0(0-27)$ & $0(0-15)$ & $2.5(0-27)$ & $1.5(0-61)$ & $2(0-16)$ \\
\hline Orientation (max: 5$)$ & $5(3-5)$ & $5(3-5)$ & $5(4-5)$ & $5(3-5)$ & $5(5-5)$ & $5(5-5)$ \\
\hline Immediate memory (max: 15) & $15(9-15)$ & $15(13-15)$ & $13(8-15)$ & $13.5(9-15)$ & $15(14-15)$ & $15(10-15)$ \\
\hline Modified BESS (max: 30) & $2(0-11)$ & $1(0-10)$ & $2(0-9)$ & $8(0-30)$ & $0.5(0-10)$ & $12(0-30)$ \\
\hline Coordination (max: 1) & $1(1)$ & $1(1)$ & $1(1)$ & $1(1)$ & $1(1)$ & $1(1)$ \\
\hline TOTAL SCAT3 score (max: 215 ) & $30(21-45)$ & $31(21-76)$ & $28(17-43)$ & $40.5(23-70)$ & $33(28-113)$ & $42(29-79)$ \\
\hline
\end{tabular}

higher $(P<0.001)$ total SCAT3 scores for male footballers with cerebral palsy and blindness, compared with male footballers without disability. Comparison of total SCAT3 scores demonstrated no significant differences between male footballers with learning disability and male footballers without disability.

Compared female footballers without disability, female footballers $\Omega$ h deafness scored significantly lower $(P=0.003)$ for total concentration, higher for balance testing

TABLE 3. Comparison of Mann-Whitney-Wilcoxon P-values Comparing $\mathrm{N} \sim$ ncussed Male Disability Footballers With Nondisability 2 ballers for Each Section Score of SCAT3 Assessment

\begin{tabular}{|c|c|c|c|}
\hline & $\begin{array}{l}\text { Learning } \\
\text { Disability }\end{array}$ & $\begin{array}{l}\text { Cerebral } \\
\text { Palsy }\end{array}$ & Blind \\
\hline \multicolumn{4}{|c|}{$\begin{array}{l}\text { Male squad comparison for total } \\
\text { number of symptoms score }\end{array}$} \\
\hline Nondisability & 0.053 & $<0.001^{*}$ & $0.001 *$ \\
\hline \multicolumn{4}{|c|}{$\begin{array}{l}\text { Male squad comparison for } \\
\text { symptom severity score }\end{array}$} \\
\hline Nondisability & $0.043^{*}$ & $<0.001^{*}$ & $0.001 *$ \\
\hline \multicolumn{4}{|c|}{$\begin{array}{l}\text { Male squad comparison for } \\
\text { orientation score }\end{array}$} \\
\hline Nondisability & 0.664 & 0.708 & 0.100 \\
\hline \multicolumn{4}{|c|}{$\begin{array}{l}\text { Male squad comparison for } \\
\text { immediate memory score }\end{array}$} \\
\hline Nondisability & $<0.001^{*}$ & $<0.001^{*}$ & 0.057 \\
\hline \multicolumn{4}{|c|}{$\begin{array}{l}\text { Male squad comparison for total } \\
\text { concentration score }\end{array}$} \\
\hline Nondisability & 0.096 & 0.056 & $0.011^{*}$ \\
\hline \multicolumn{4}{|c|}{ Male squad delayed recall score } \\
\hline Nondisability & $<0.001 *$ & 0.085 & $0.050 *$ \\
\hline \multicolumn{4}{|c|}{$\begin{array}{l}\text { Male squad comparison for total } \\
\text { balance score }\end{array}$} \\
\hline Nondisability & 0.814 & $<0.001^{*}$ & 0.183 \\
\hline \multicolumn{4}{|c|}{$\begin{array}{l}\text { Male squad comparison for total } \\
\text { SCAT3 score }\end{array}$} \\
\hline Nondisability & 0.068 & $<0.001 *$ & $0.032 *$ \\
\hline
\end{tabular}

4 | www.cjsportmed.com
$(P<0.001)$, and higher for total SCAT3 $(P<0.001)$ with greater ranges (minimum and maximum both higher) than female athletes without disability (Table 4).

Table 5 compares the results for each group with the classification cut-off ranges calculated by Hanninen et al ${ }^{17}$ and demonstrates many large percentage differences within classification ranges between each disability footballer group, professional ice hockey players from Finland, and also male and female footballer groups without disability.

\section{DISCUSSION}

This study confirms that significant differences exist between nonc ssed SCAT3 subscores for male footballers with learning bility, cerebral palsy, blindness and female footballers with deafness, and their respective male and female footballer groups living without disability. It is not known how these differences affect neurocognitive function or compare with SCAT3 scores after head injury or concussion; however, the assessment of baseline values is important in clinical practice when determining diagnosis and

TABLE 4. Comparison of Mann-Whitney-Wilcoxon P-values Comparing Non ussed Female Athletes Without Disability and Female Dea $\_$letes for Each Section Score of SCAT3 Assessment

\begin{tabular}{lc}
\hline & Mann-Whitney \\
\hline Total number of symptoms (maximum possible 22) & $\boldsymbol{P}$ \\
Symptom severity score (maximum possible 132) & 0.130 \\
Orientation score (maximum possible 5) & 0.141 \\
Immediate memory score (maximum possible 15) & 0.451 \\
Total concentration score (maximum possible 5) & 0.925 \\
Delayed recall score (maximum possible 5) & $0.003^{*}$ \\
Modified balance error scoring system testing & 0.391 \\
(maximum possible 30) & $<0.001^{*}$ \\
Coordination & 1.0 \\
TOTAL SCA & $<0.001^{*}$ \\
\hline
\end{tabular}

*Mann-Whitney-Wilcoxon independent samples $P$-value $<0.05$.

Copyright (C) 2016 Wolters Kluwer Health, Inc. All rights reserved. 
TABLE 5. Comparison of SCAT3 Normative Classification Reference Ranges for Healthy Male Professional Ice Hockey Players ${ }^{17}$ Compared With Footballer Groups With and Without Disability

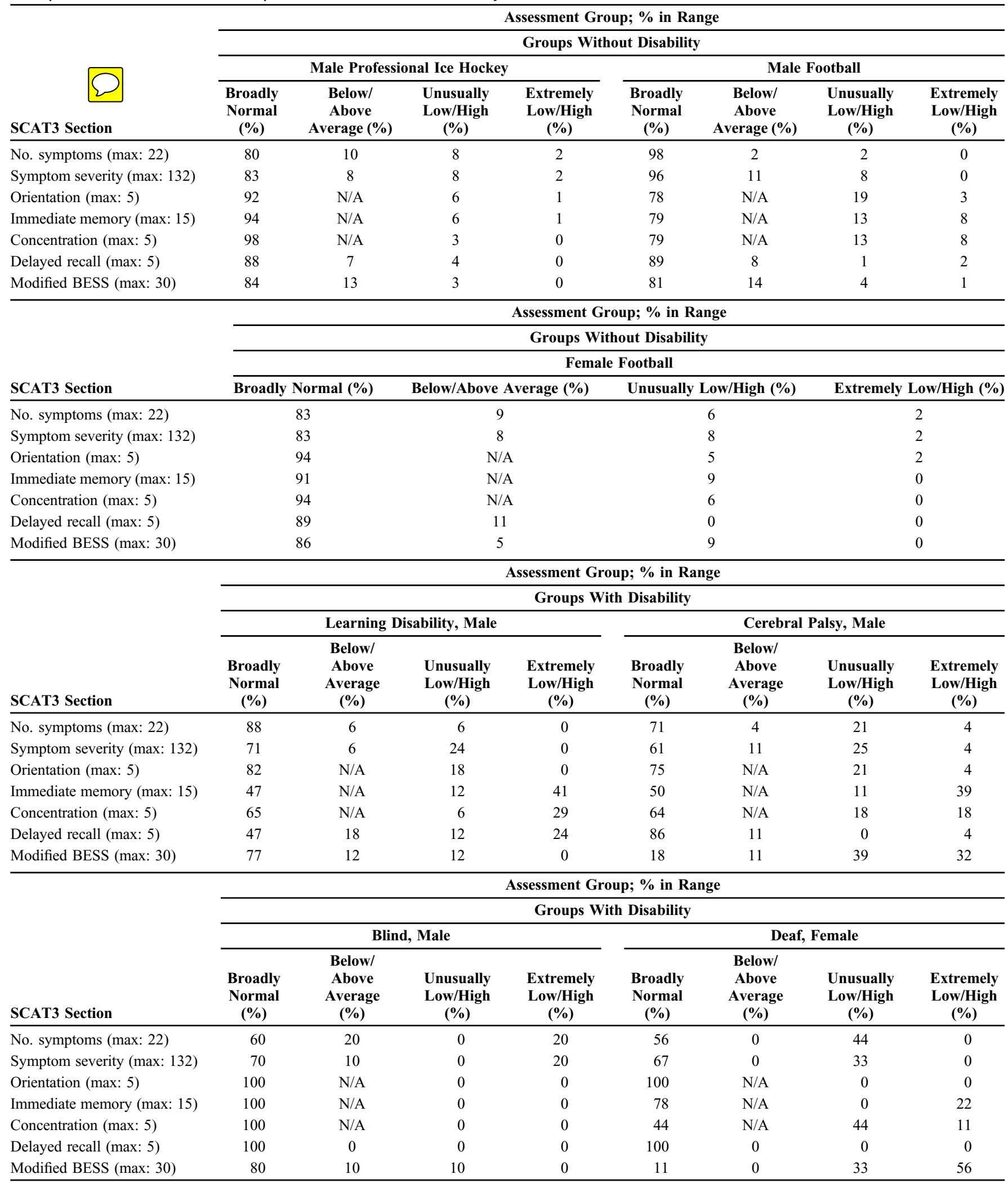


management of a player after head injury. This suggests there is a need to develop greater understanding of the clinimetric properties and validity of each SCAT3 subscore against a gold standard and the reproducibility of SCAT3 findings. Although the use of SCAT3 as a baseline tool for evaluating concussion is not validated, multiple differences seen in non ${ }^{2}$ ngussed footballers within this study clearly demonstra1 2 ere are cross-sectional neurocognitive differences between footballers living with and without disability. These results suggest the SCAT3 assessment tool may not be applicable for athletes with disability and therefore testspecific validation and reliability assessments are required for these different user groups.

Male footballers with learning disability had significantly lower cognitive scores for immediate memory and delayed recall compared with male footballers without disability. The sport eligibility criteria for those with learning disability r $\mathrm{r}$ e significant impairment in intellectual functioning (de $Q$ as a 'Full Scale IQ score of 75 or lower) and limitation in intellectual functioning and adaptive behavior expressed in conceptual, social, and practical adaptive skills, which originates before the age of 18 years. Therefore, these differences in cognitive function are, perhaps, entirely expected. $.6,7,30$ This suggests that (1) SCAT3 cognitive assessment may not be appropriate and modified SCAT3 assessment is needed for this subgroup; and (2) clinicians should always consider the presence of athlete learning disability, which could be diagnosed, undiagnosed, or unknown.

Male blind footballers scored higher than male footballers without disability for total concentration and delayed recall, which supports studies among blind n letes showing improved brain plasticity and neurocognit function resulting in improved memory. ${ }^{31,32}$ The impact of a head injury and the sensitivity of neurocognitive changes after concussion are not known for blind footballers, which is surprising considering that head and face injuries in this group are relatively common injuries. ${ }^{33}$ Cerebral palsy and neuralimpairment conditions eligible for cerebral palsy football are defined by the World Health Organization's International Classification of Functioning as limiting a person's "functioning," [inclusive of body structures (eg, limbs), body functions (eg, intellectual function), activities (eg, walking), and participation (eg, playing sport)], which in turn may cause "disabilities," such as impairments, activity limitations, and participation restrictions. ${ }^{34,35}$ Therefore, higher numbers of errors on balance tests and a lower cognitive SCAT3 score are to be expected, and these differences again suggest that the SCAT3 may not be an appropriate neurocognitive test for this subpopulation of elite athletes with disability.

Compared $\sqrt{ }$ their counterparts without disability, male footballers w erebral palsy and blindness reported significantly different and greater numbers of concussive symptoms. Male footballers with learning disability, cerebral palsy, and blindness have significantly higher baseline concussion symptom severity scores than male footballers without disability. The reasons for these differences are unclear and may vary across disability and population subgroups. The results suggest that SCAT3 symptoms are a more normal experience for footballers with learning disability, cerebral palsy, and blindness and, when reported, are experienced more severely than for footballers without disability.

Total SCAT3 scores for fema otballers with deafness were significantly higher than fotballers without disability, whereas deaf athletes scored significantly higher for total concentration and balance testing. Only a small proportion of people with hearing loss have problems with balance, ${ }^{36}$ and this is more likely a result of an acquired acoustic trauma or ototoxins. ${ }^{37}$ Use of BESS within SCAT3 is problematic, because proprioception can be learnt and improved by children with deafness ${ }^{38}$ and is also a common method used by sporting populations to prevent injury. ${ }^{39}$ It was beyond the scope of our study to analyze use and concordance of proprioception programs for individual athletes, but this may have affected results. SCAT3 guidance does not suggest that clinicians take such programs into account.

Our results for each disability football group were compared with Hanninen et al reference ranges: "Broadly normal," Below/above average," "Unusually low/high," and "Extremely low/high." 17 Many large differences are evident between percentages of athletes within SCAT3 subsection score classification cut-off ranges, when comparing each footballer disability group and athletes without disability. The majority of percentages were much lower; however, blind male footballers all scored "broadly normal" for orientation, immediate memory, concentration and delayed recall, and deaf female footballers all scored "broadly normal" for orientation and delayed recall. These results further suggest that reference ranges for athletes without disability are not appropriate for athletes with disability, and differences are seen in neurocognitive function at baseline between disability groups.

The results presented in this study relate to relatively small sample populations and limited ranges of disabilities and forms of adapted football; however, the results strongly suggest that further studies are required to understand the complexities of concussion diagnosis in disability sport. Future research should therefore include larger sample populations, athletes with other disabilities, and athletes from other sports to develop more robust versions of SCAT for disability sport.

Little is known about concussion for athletes with disability, and previous guidelines have therefore not been able to provide more specific guidance. Future concussion consensus group research recommendations have suggested the looking at efficacy for inclusion of vision tests such as King-Devick and clinical reaction time tests, which will have limitations for many athletes with disability including those with visual impairment ${ }^{8,40,41}$ or neuromuscular impairment, such as cerebral palsy. Furthermore, learning disability often goes unrecognized in sporting environments. In England (and many other countries), there are no records of the number of people with learning disabilities, ${ }^{42}$ so it is unsurprising that the incidence of learning disability in sport also remains unknown. The AMSSM Position Statement on concussion in sport ${ }^{12}$ recognized that learning and attention disorders share many common features with concussion, such as difficulty with memory, attention, and concentration. ${ }^{18-20}$ These are included in SCAT3 at baseline and 
pos cussion generating clinical implications. AMSSM the e concluded that baseline testing was "more important in those with learning disability or attention disorders if testing is going to be used postinjury to assist in return-toplay decisions." "12 Our results support the importance of this conclusion, as we found noncussed athletes with learning disability, cerebral palsy, $\mathrm{d} \odot$ ess, and blindness share many features with concussion when measured with SCAT3. Although it is not known how these SCAT3 scores may change when measured post ussion for athletes within these disability groups, the rences in numerical subscores at baseline do not support the use of the whole SCAT3 as an assessment tool for athletes with disability as they will change the sensitivity and specificity.

Normative no cussed neurocognitive differences between footballers h disability have important implications on the sensitivity and specificity of many other clinical tests, such as musculoskeletal and neuromuscular tests. All of these clinical tests require neural (for movement) and cognitive elements to be performed and, to our knowledge, none have been validated in disability populations. Furthermore, if injury rates within disability sport are unknown ${ }^{8,43}$ and the diagnostic accuracy of clinical tests for athletes with disability are suspected to be different, then barriers to accurate diagnosis, improved recognition and management of concussion, and other sports injuries may hamper research within disability sport.

\section{CONCLUSIONS}

The results of this study suggest that significant crosssectional differences exist between SCAT3 baseline section scores for footballers with disability and footballers without disability. Therefore, caution is needed when interpreting baseline SCAT3 scores for athletes with disability. Normative values and post ussion SCAT3 score sensitivity for athletes with dis $2 .-1$ y remain unclear. Clinicians therefore must consider the presence of disability in athletes when using SCAT3, which has important implications in wider clinical practice (eg, the presence of learning disability may be unknown, undiagnosed or not considered). There is an evident need to develop greater understanding of the clinimetric properties (ie, validity and reliability) of each SCAT3 subtest. Concussion consensus guidelines should recognize these differences and produce guidelines and assessment tools that are specific for the growing number of elite athletes living with disability.

\section{ACKNOWLEDGMENTS}

The authors thank The Football Association for their collaborative support in producing this paper and in particular Ian Beasley and Sue Cheadle who helped make this research happen.

\section{REFERENCES}

1. World Health Organization. World Report on Disability. WHO; Geneva, Switzerland: 2011. Available at: http://www.who.int/disabilities/world_ report/2011/en/index.html. Accessed June 9, 2016.
2. Webborn N. The disabled athlete. In: Brukner P, Kahn K, eds. Clinical Sports Medicine. New York, NY: McGraw-Hill, 2006.

3. Fernhall B, Heffernan K, Jae SY, et al. Health implications of physical activity in individuals with spinal cord injury: a literature review. $J$ Health Hum Serv Adm. 2008;30:468-502.

4. van der Ploeg HP, van der Beek AJ, van der Woude LH, et al. Physical activity for people with a disability. Sports Med. 2004;34:639-649.

5. English Federation of Disability Sport. Participation in Individual Sports. Active People Survey 7. Sport England. Available at: www.efds.co.uk/ assets/0000/8377/APS7_Full_data_-_by_sport_January_2013.pdf.

6. Explanatory Guide to Paralympic Classification. Paralympic Summer Sports. Internation ralympic Committee, 2015. Available at: http:// www.paralympic. 2 tes/default/files/document/150915170806821_ 2015_09_15\%2BExplanatory\%2Bguide\%2BClassification_summer\% 2BFINAL\%2B.pdf.

7. Laym 'ruide to Classification in Paralympic Winter Sports. International Paraly (20i) Committee; 2012. Available at: http://www.paralympic.org/ sites/deraur/files/document/121203164523073_WinterSportLaymens.pdf.

8. Wei Van Mechelen W, Fuller C, et al. Sport injuries sustained by athle ith disability: a systematic review. Sports Med. 2016:1-3.

9. Carney N, Ghajar J, Jagoda A, et al. Concussion guidelines step 1: systematic review of prevalent indicators. Neurosurg. 2014;75:S3-S15.

10. McCrory P, Davis G, Makdissi M. Second impact syndrome or cerebral swelling after sporting head injury. Curr Sports Med Rep. 2012;11:21-23.

11. McCrory P, Meeuwisse W, Aubry M, et al. Consensus statement on concussion in sport - the 4th international conference on concussion in sport held in Zurich. Br J Sports Med. 2013;47:250-258.

12. Harmon KG, Drezner AJ, Gammons M, et al. American medical society for sports medicine position statement: concussion in sport. Clin J Sport Med. 2013;23:1-18.

13. McCr Meeuwisse WH, Aubry M, et al. SCAT3. Br J Sports Med. 2013; 9-262. Available at: http://bjsm.bmj.com/content/47/5/259. full.pdf.

14. King D, Brughelli M, Hum P, et al. Assessment, management and knowledge of sport-related concussion: systematic review. Sports Med. 2014; 44:449-471.

15. Mitten MJ. Emerging legal issues in sports medicine. St John's L Rev. 2002.76:5-86.

16. Bo (m) Friern, Hospital Management Committee [1957] 2 All ER 118-128.

17. Ha m T, Tuominen M, Parkkari J, et al. Sport concussion assessment tool 3rd edition -normative reference values for professional ice hockey players. J Sci Med Sport. 2016;19:636-641.

18. Zuckerman SL, Lee YM, Odom MJ, et al. Baseline neurocognitive scores in athletes with attention deficit-spectrum disorders and/or learning disability. J Neurosurg Ped. 2013;12:103-109.

19. Elbin RJ, Kontos AP, Kegel N, et al. Individual and combined effects of LD and ADHD on computerized neurocognitive concussion test performance: evidence for separate norms. Arch Clin Neuropsychol. 2013;28: 476-484.

20. Konicarova J, Bob P, Raboch J. Balance deficits and ADHD symptoms in medication naive school-aged boys. Neuropsychiatr Dis Treat. 2014; 10:85-88.

21. Broglio SP, Cantu RC, Gioia GA, et al. National Athletic Trainers' Association Position Statement: Management of Sport Concussion. J Athl Train. 2014;7:7.

22. Giza CC, Kutcher JS, Ashwal S, et al. Summary of evidence-based guideline update: evaluation and management of concussion in sports: report of the Guideline Development Subcommittee of the American Academy of Neurology. Neurology. 2013;80:2250-2257.

23. Yengo-Kahn AM, Hale AT, Zalneraitis BH, et al. The Sport Concussion Assessment Tool: a systematic review. Neurosurg Focus. 2016;40:E6.

24. McLeod TC, Bay RC, Lam KC, et al. Representative baseline values on the Sport Concussion Assessment Tool 2 (SCAT2) in adolescent athletes vary by gender, grade, and concussion history. Am J Sports Med. 2012; 40:927-933.

25. Putukian M, Echemendia R, Dettwiler-Danspeckgruber A, et al. Prospective clinical assessment using Sideline Concussion Assessment Tool-2 testing in the evaluation of sport-related concussion in college athletes. Clin J Sport Med. 2015;25:36-42.

26. McCrory P, Johnston K, Meeuwisse W, et al. Summary and agreement statement of the 2nd International Conference on Concussion in Sport, Prague 2004. Br J Sports Med. 2005;39:196-204. 
27. Gessel LM, Fields SK, Collins CL, et al. Concussions among United States high school and collegiate athletes. J Athl Train. 2007;42: 495-503.

28. Dvorak J, Junge A, Fuller C, et al. Medical issues in women's football. Br J Sports Med. 2007;41(suppl 1):i1.

29. Dvorak J, McCrory P, Kirkendall DT. Head injuries in the female football player: incidence, mechanisms, risk factors and management. $\mathrm{Br} J$ Sports Med. 2007;41(suppl 1):i44-6.

30. (va) ble at: www.inas.org/member-services/eligibility-and-classification.

31. 2 alotto A, Lam JS, Proulx MJ. Congenital blindness improves semantic and episodic memory. Behav Brain Res. 2013;244:162-165.

32. King AJ. Crossmodal plasticity and hearing capabilities following blindness. Cell Tissue Res. 2015;361:295-300.

33. Webborn N, Cushman D, Blauwet CA, et al. The epidemiology of injuries in football at the London 2012 paralympic gam $1 \& R$. 2015. In press.

34. World Health Organization (WHO). Internation assification of Functioning, Disability and Health. Geneva, Switzerland: WHO; 2001.

35. Novak I, McIntyre S, Morgan C, et al. A systematic review of interventions for children with cerebral palsy: state of the evidence. Dev Med Child Neurol. 2013;55:885-910.

36. Palmer T, Weber KM. The deaf athlete. Curr Sports Med Rep. 2006;5: 323-326.
37. Cheng AC, Cunningham LL, Rubel EW. Mechanisms of hair cell death and protection. Curr Opin Otolaryngol Head Neck Surg. 2005; $13: 343-348$

38. Majlesi M, Farahpour N, Azadian E, et al. The effect of interventional proprioceptive training on static balance and gait in deaf children. Res Dev Disabil. 2014:35:3562-3567.

39. Schiftan GS, Ross LA, Hahne AJ. The effectiveness of proprioceptive training in preventing ankle sprains in sporting populations: a systematic review and meta-analysis. $J$ Sci Med Sport. 2015;18:238-244.

40. Eckner JT, Kutcher JS, Richardson JK. Between-seasons test-retest reliability of clinically measured reaction time in National Collegiate Athletic Association Division I athletes. J Athl Train. 2011;46:409-414.

41. Eckner JT, Richardson JK, Kim H, et al. A novel clinical test of recognition reaction time in healthy adults. Psychol Assess. 2012;24: 249-254

42. Em E, Hatton C, Robertson J, et al. People with Learning Disabilitie in ingland 2011. Improving Health and lives: Learning Disability Observatory. Available at: http://www.improvinghealthandlives.org.uk/ securefiles/151124_1205//IHAL2012-04PWLD2011.pdf.

43. Ahmed O, Hussain A, Beasley I, et al. Enhancing performance and sport injury prevention in disability sport: moving forwards in the field of football. Br J Sports Med. 2015;49:566-567. 